\title{
Modeling and simulation tools in mechanical design education: what didactical determinants?
}

\author{
${ }^{1}$ Youssoupha GUEYE ${ }^{1,2}$, ${ }^{2}$ Hamid ABOUCHADI, ${ }^{3}$ Mourad ABOUELALA, ${ }^{4}$ Mourad Taha \\ JANAN
}

${ }^{1}$ ENSET, Mohammed V University in Rabat Morocco, ÉNSETP, Université Cheikh Anta Diop de Dakar Sénégal

Email : youssoupha1.gueye@ucad.edu.sn

${ }^{2}$ ENSET, Mohammed V University in Rabat Morocco

Email : abouchadi@gmail.com

${ }^{3}$ ENSET, Mohammed V University in Rabat Morocco

Email: m.abouelala@um5s.net.ma

${ }^{4}$ ENSET, Mohammed V University in Rabat Morocco

Email: m.tahajanan@um5s.net.ma

Article History: Received:11 January 2021; Accepted: 27 February 2021; Published online: 5 April 2021

\begin{abstract}
This article presents the results of a study on the integration of modeling and simulation tools in the teaching of mechanical design. Indeed, optimisation of the design process often uses modelling and simulation tools in mechanical design activities. Thus, to meet the needs of the labour market, training situations in this field we use communication and information technology. In particular, digital tools are used for the development of virtual models intended for sizing and optimisation, and/or validating the behaviour and performance of a system, component, or process. However, their use in the teaching-learning activities of mechanical design give rise to many problems. These problems are often related to the educational use of these tools; the ergonomics of their interfaces and the didactic interaction. Thus, this study proposes in the framework of mechanical design teaching, through a case study, to analyze determinants of the didactic activity of the teacher in order to identify the contingencies of the didactic action. It presents didactic determinants on the process of teaching mechanical design using modeling and simulation tools.
\end{abstract}

Keywords: Didactical determinants, modeling tools, mechanical design.

\section{INTRODUCTION}

Today more than ever, the need for competitiveness requires designing faster, better and cheaper than competitors to penetrate an increasingly dense and complex market. That's why the efficiency of products design and optimization is the ongoing challenge of industrial production units. One of the possible answers to satisfy this imperative need is a rusty and efficient training of technicians and engineers with powerful tools and relevant design procedures.

In the field of mechanical design, industrial production units use modeling and simulation tools in mechanical design work [1]. In response to the problem of training-employment adequacy, technological education institutions introduce these same modeling and simulation tools into mechanical design teaching. The introduction of software or modeling tools in teaching-learning activities in industrial science and technology opens up new opportunities for teaching mechanical design in higher technological education institutions [2-3]. Otherwise, the use of an artifact, such as a modeling and simulation tool in teaching-learning activities, presupposes the consideration and modification of instrumental and ergonomic genesis, a change of teaching practices and conceptualizations of these practices [4].

The role of modeling tools in the design process has been the subject of many works [5-6]. The present study is carried out in this framework and focuses on the use of modeling tools in teaching practices of mechanical design teachers. With the new environment of modeling tools and their potentialities, the mechanical design teacher will have to question their use in the organization and implementation of teaching-learning situations. What problems do modeling and simulation tools confront to teachers in their teaching practices, especially in mechanical design? Otherwise, how to help teachers to understand the modeling and simulation tools in this context? The answer to the above questions justifies this study, with the aim of contributing to the improvement of the quality of mechanical design teaching-learning at the level of higher technological education institutions. It involves analyzing the joint activity of teachers and students during the use of modeling tools in mechanical design. Thus, during the teaching-learning process, it will be necessary to identify the components of the appropriation process of the adopted tools and the resulting problems, related to the teacher, in the sense of proposing lines of reflection in order to improve pedagogical practices in mechanical design teaching. The present study explores qualitative 
aspects of the educational use of modeling and simulation tools in a didactic context at the level of higher technological education institutions.

\section{MECHANICAL DESIGN AND MODELING TOOLS}

The design of technical systems is defined by the sum of operations that allows a person to explain an idea by giving it a tangible or virtual reality [7]. It comes from a complex process that consists in predicting materiality object that does not yet exist and exists only in the minds of those who conceive it [8]. In this regards, it consists in giving a set of propositions to describe a product (shape, dimension, manufacturing possibilities) and answer globally to specifications. From an operational point of view, mechanical design reveals four categories of design: routine design, redesign, innovative design and creative design. All of these categories share a common thread in design activities: knowing and understanding the needs of the customer; defining the problem to solve in order to satisfy the needs; conceptualizing the solution; performing the analysis, optimizing the proposed solution; verifying the obtained design, to see if it resolves the initial customers' needs [9].

The following three important steps (Figure 1) are often found in various existing methodologies: definition of the problem to satisfy the requirements; the conceptual definition, which sets up the functional structure; the physical principles and proposes a concept; the detailed definition, which provides a complete description of the design [10].

\begin{tabular}{|c|c|c|c|c|c|c|c|}
\hline \multirow{2}{*}{$\begin{array}{c}\text { Expression } \\
\text { of need }\end{array}$} & \multirow[b]{2}{*}{ Specifications } & \multicolumn{3}{|c|}{ Preliminary conception } & \multirow{2}{*}{$\begin{array}{c}\text { Product } \\
\text { concepts } \\
\text { folder }\end{array}$} & \multirow{2}{*}{$\begin{array}{c}\text { Detailed } \\
\text { design }\end{array}$} & \multirow{2}{*}{$\begin{array}{l}\text { Definition } \\
\text { folder }\end{array}$} \\
\hline & & $\begin{array}{c}\text { Conceptual } \\
\text { design }\end{array}$ & Concepts & $\begin{array}{c}\text { Architectural } \\
\text { design }\end{array}$ & & & \\
\hline
\end{tabular}

Figure 1. Product design process

At certain stages, the resort to modeling could be systematic. This consideration on design and modeling focuses on the use of modeling and simulation tools in the teaching-learning activities of mechanical design at university vocational institutions.

\section{PROBLEM}

The adoption of modeling and simulation tools in the teaching of mechanical design in industrial sciences and technologies has produced qualitative transformations in teaching practices. Therefore, it would be interesting to question about the appropriation of modeling and simulation tools by teachers in their teaching practices. It is a question of describing determinants of the teacher's didactic activity, apprehended in the internal and external interaction processes. In this respect, the understanding of the mechanisms involved, through such processes, constitutes a didactic challenge, a guarantee of the quality of the learning acquired.

\section{BACKGROUND AND THEORETICAL FRAMEWORK}

To have a better understanding of the phenomenon we are interested in, the present study is based on an approach that articulates three theoretical concepts. First of all, it presents the instrumental approach developed by Rabardel, which relies on the importance of instrumental mediation [11]. Then, the Engeström model on the "basic structure of an activity" which takes into account the social or collective dimension of the activities as well as the media coverage of the actions with the tools mobilized in the observed contexts. Then the Technological Pedagogical Content Knowledge (TPCK) analysis model, adapted from Mishra and Koehler, is considered to understand the different influences that determine the teaching practices of teachers in the use of modeling tools [12].

\subsection{Historical perspective on the analysis of teaching practices}

Historically, studies on teaching practices have been part of the "process-product" paradigm for a long time. The study of teaching process was reduced to observable behaviors in order to determine the effectiveness of the teacher [13-14]. Further studies focused, under a cognitivist paradigm, on "teacher thinking". They conceived cognition as an essential control instance of teaching practice [15]. Then the emergence of the "ecological" paradigm made it possible to take into account the importance of the "situation" in which the teaching takes place. Today, the interactionist and integrative paradigm clarify the articulation of several types of variables concerning the teacher, the student and the situation (actors and learning environment), to understand the teaching practice [16-17]. This study fits into this last paradigm. However, it is necessary to make difference in the work on teaching practice the concept of "teacher practice" from that of «teaching practice». In fact, teacher practice includes teaching practice and others which take place outside the classroom. Teaching practice, indeed takes place mainly in class, in the presence of students [18]. It includes three phases: pre-active, interactive and post-active. The preactive phase is the planning that the teacher carries out alone or with his colleagues. The interactive phase refers to the intervention with students, whereas the post-active phase refers to actions concerning the evaluation of teaching [19]. The present research interested in the three phases.

\subsection{Instrumental approach}


The use of modeling tools in the teaching of mechanical design is a didactical matter. Didactics is the study of cognitive issues in a teaching-learning situation within a discipline [20]. According to Vergnaud, it is the "study of the processes of transmission and appropriation of knowledge in what they have as specific content, with the aim of improving these processes [21-22]. Our consideration on design and modeling take place in a didactic context in university vocational institutions.

The present work finds its theoretical basis in the instrumental approach developed by Rabardel [11]. This approach is based on the importance of instrumental mediation and distinguishes between an artifact and an instrument. Rabardel shows that the instrument comprises, on one hand, a material or symbolic artifact produced by the user or by others, and on the other hand, one or more associated use patterns that result from a proper construction of the subject or the appropriation of pre-existing social schemes. The transition from the artifact to the instrument refers to a process of instrumental genesis that, according to Rabardel [11], through usage, marks the gradual evolution of the use of the artifact. Rabardel distinguishes in the instrumental genesis two processes: instrumentalization (oriented towards the artifact) and instrumentation (oriented towards the subject). The process of instrumentalization concerns the artifactual component of the instrument by the attribution of function (s) whereas the subject-oriented instrumentation is constitutive of the capacity of the subject "to adapt to new constraints, new objects" at the genesis of the schemes.

\subsection{Activity theory and modeling of student-software teaching-learning interactions}

The present work, among other studies, refers to the activity theory that deals with human activity, considered as a socially situated activity such as that related to work or learning [23]. It has its origins in the works of Vygotsky, who considered that the development of human behavior was first and foremost mediated by the use and creation of material or symbolic cultural artifacts [24]. For Engeström, Vygotsky is the symbol of the first generation of this theory [25].

Léontiev develops the second generation, emphasizing the importance of the differentiation between individual action and collective action, and taking into account the complex interactions between the individual and his community [26].

Engeström later developed a systemic model based on the first two generations, adding the socioinstitutional infrastructure of the activity, meaning that the elements of the community, work rules and organization [27]. It places the individual at the heart of a system of activity composed of six interrelated poles (subject, tool, rules, division of labor, community, object) as depicted in figure 2. We refer to Engeström's systemic model for modeling the teaching-learning activity of mechanical design using CAD software to answer the several questions that arise and related to the improvement of effectiveness of teaching-learning.

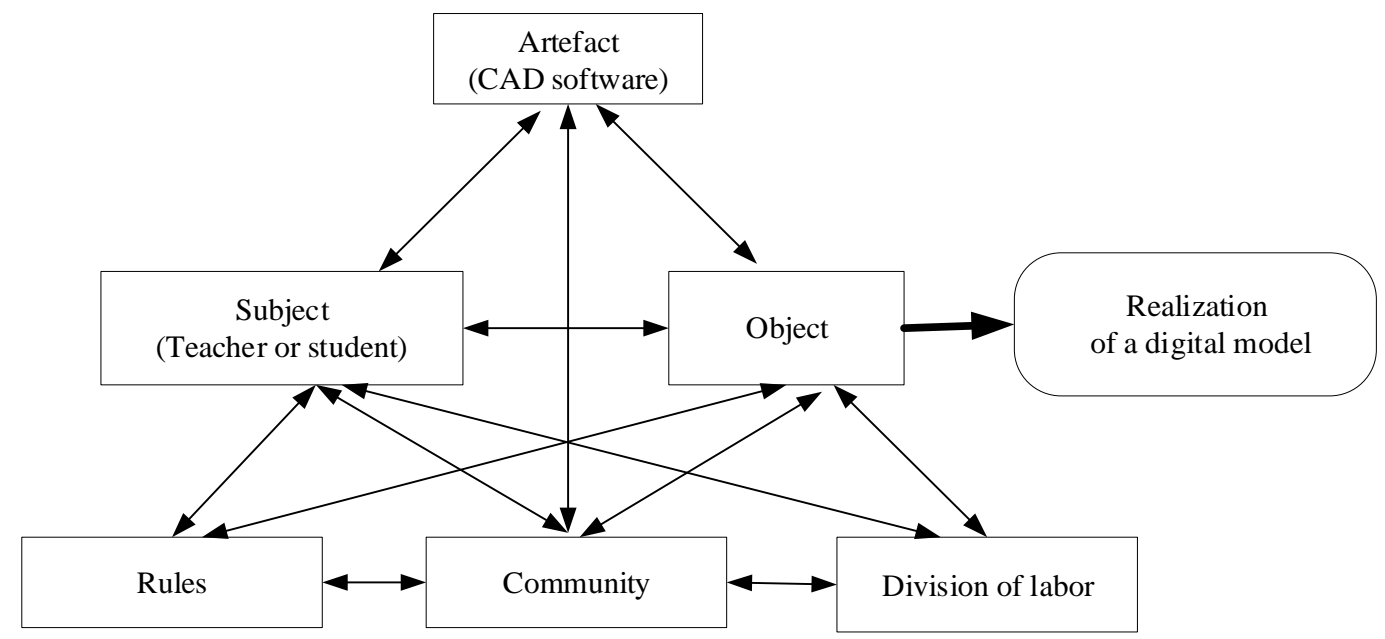

Figure 2. Schematization of the Subject/ CAD software interaction according to the activity theory due to Engström

This model expresses the relationship between the subject (teacher or student) and the object of the activity. The subject-object relationship is mediated by the concept of tool. Tool mediation is a means of transmitting a certain culture or knowledge. The subject realizes the object of the activity, but at the same time, the properties of the object transform the subject by increasing his experience. Community-subject and community-object relations are mediated by the concepts of rules and division of labor, which also contain the cultural heritage of the situation. It is however important to specify the different poles in this study. The Subject is an individual or sub-group that the observer has chosen to analyze, in our work he is represented by the teacher or the student. The Object is the transformation of the environment that is targeted by the activity (task to be accomplished, objective to achieve). Here, it is the realization of a digital model of a technical system. The tools or artifact are the material or symbolic 
tools that mediate the activity (software or tools for modeling and simulation). The community is the subjects (or subgroups) that share the same object such as industrialists, other universities and institutes, designers, developers and users of CAD software. The division of labor includes both the horizontal distribution of actions between subjects and members of the community, and the vertical hierarchy of powers and statutes, such as the pedagogical leaders of the university, departments, and teachers. Rules refer to the implicit and explicit norms, conventions, habits ... that maintain and regulate actions and interactions within the system.

4.4. Teaching practices analysis model

We refer to the TPCK analysis model adapted from Mishra and Koehler, to understand the different influences [12] that determine the teaching practices of teachers in the use of modeling and simulation tools in mechanical design. Their model was inspired by the Pedagocical Content Knowledge (PCK) which is based on the concept of disciplinary content pedagogy with two dimensions: pedagogical knowledge and disciplinary knowledge. Mishra and Koehler associate these two dimensions with knowledge of technologies including knowledge of the use of technological tools. The TPCK is a model of educational technology used to describe the knowledge that a teacher needs to acquire when incorporating new technologies into educational practices [28].

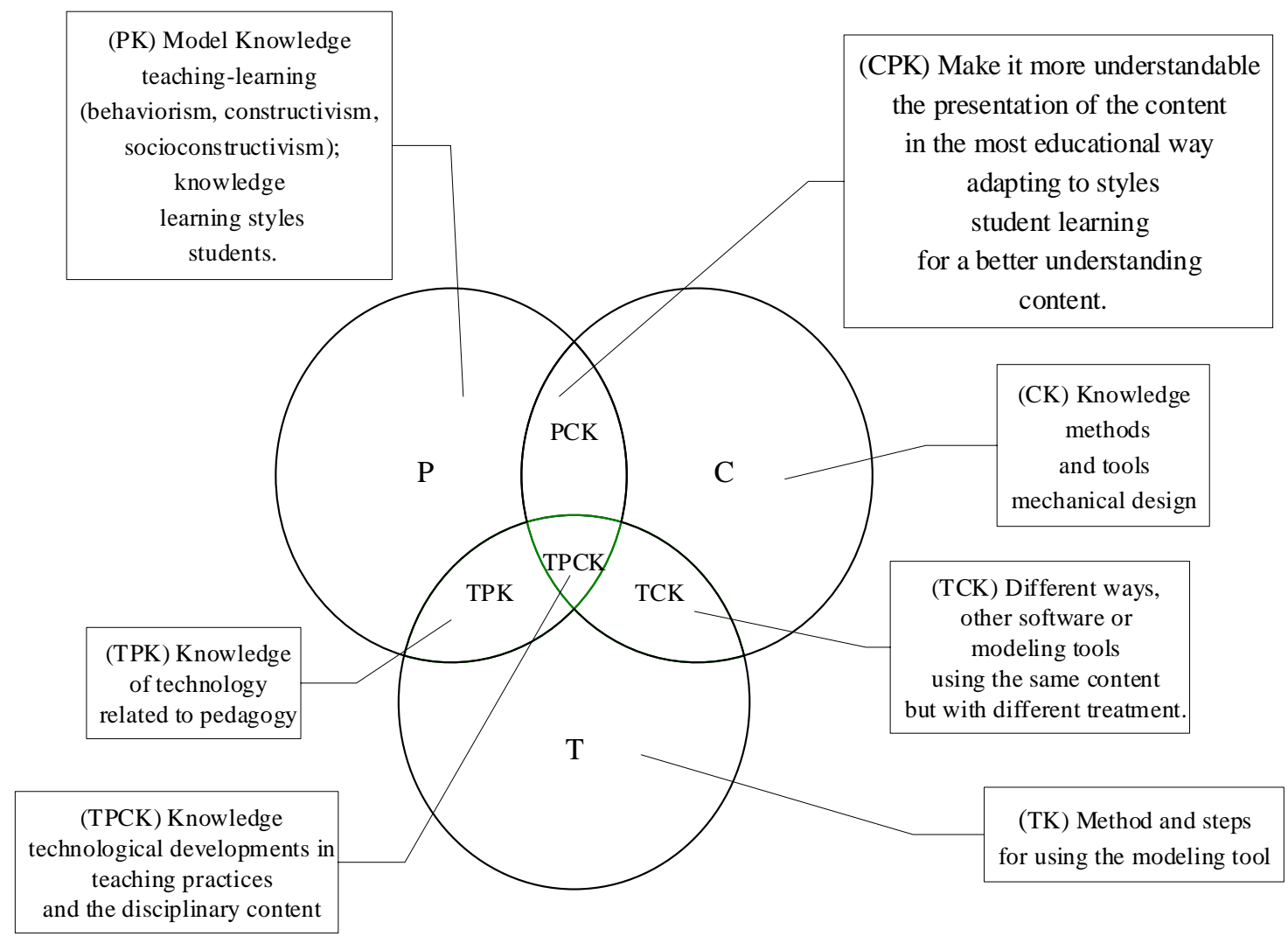

Figure 3. Application of the TPCK model in the case of CAD education

Figure 3 presents the elements of the TPCK model approach applied to the case of teaching mechanical design through the use of modeling and simulation tools. It summarizes the different skills that can be used by the teacher in his interaction with the CAD software.

\section{OBJECTIVE OF THE RESEARCH}

In general terms, the present research contributes to the improvement of the quality of the teaching-learning process of mechanical design at the level of higher technological education institutions. More specifically, it proposes to analyze factors likely to intervene in the management of the contingencies of the teaching process. This will be organized through a joint activity related to the use of modeling and simulation tools as part of mechanical design education.

\section{METHODOLOGY}

The establishment of a methodological protocol is necessary for the reliability of the data to be collected, because it combines investigations, interviews and observations in situ. Another reason which justifies the choice of this approach lies in the fact that teachers' knowledge cannot be accessed either by the dynamics of the emerging processes of the situations, or by the sole point of view of the actor and the sense that he gives to his experience, or even the only justifications for the action he enounciates. This is why this analysis work relies on empirical 
materials from actual training situations. This leads us to adopt a triangulation of several methods and tools of investigation in order to:

- $\quad$ reduce the biases inherent in each method and thus increase the reliability and validity of the data collected;

- provide a qualitative richness and a better understanding of the phenomenon studied;

- facilitate the apprehension of processes that are not directly observable, such as the opinion of the targets.

\subsection{Case study in didactics of mechanical design}

In this type of research, several steps are possible. Since we are not in a purely quantitative approach, we have opted for a case study. This option has objective limits: the results can not be generalized. Yet, case study approaches can provide insights as they can be replicated in other situations. This work is part of a collaborative research conducted in the associated training venue that is the «Higher Normal School of Technical Education in Rabat (ENSET, Morocco) ». In this context, three teachers (Teacher1, Teacher2 and Teacher3) are involved in the research process from a theme related to the realization of a digital model of a technical system. Teachers as co-researchers are responsible for the design and implementation of pedagogical sequences. This gives them the freedom to resort to their usual practices or their choice. The principal investigator does not intervene in the design of sessions or in the execution. He remains in his role of remote observer.

\subsection{Methodological protocol and data collection tools}

The methodological protocol (figure 4) is divided into four stages. As a first step, an interview questionnaire is administered to the teacher about the observed teaching session. It aims to clarify the didactic intentions of the professor in relation to his professional uses and the institutional context of intervention. It concerns also the identification of the different tasks that will be offered to students and their succession, what knowledge is to be taught and to collect information on their professional biography. Session preparation documents are taken into consideration. Then, an observation grid is used about the observed teaching session. It seeks to give an account of the progress of the session, thus facilitating the possible analyzes in order to check the degree of coherence between the didactic approaches proposed and their effective implementation. Thirdly, a post-session interview with the teacher made it possible to review certain elements of the session, with the intention to define more precisely how the teacher adopts and adapts the modeling tool. This interview completes the teacher questionnaire in terms of information triangulation strategies. Finally, a test on the realization of a digital model is administered to students after the teaching-learning session. After the test, a questionnaire is administered to the students. It makes it possible to specify the performance of the student in his interaction with the modeling tool and to evaluate his satisfaction on the use of the modeling tool in order to detect the usability problems posed by the interface.

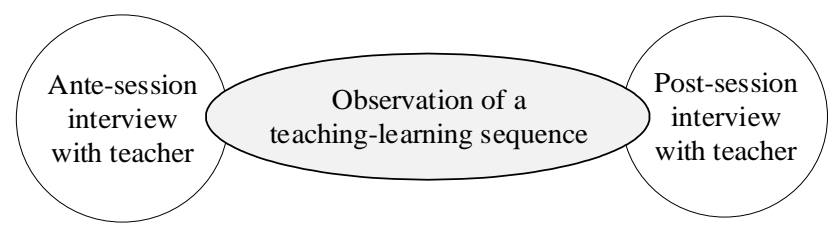

Figure 4. Data collection device

6.3. Ergonomic evaluation of the software

The criterion related to the ergonomy is not usually used, for this reason, we focus on different apects related to it. The ergonomic evaluation of the software interface aims to evaluate the degree of user-friendliness and ease of access to the different menus of the CAD software.

The ergonomics of the software interface is a quality factor for interactive systems [29]. To approach the ergonomic evaluation of a software is to pose the problem of its usability [30], its usefulness and its acceptability. Three dimensions explored by Tricot and al in the evaluation of Computer Environments for Human Learning [31]. Figure 5 presents dimensions of criteria taken into account in the evaluation of a Human Learning Computing Environment (EIAH). 


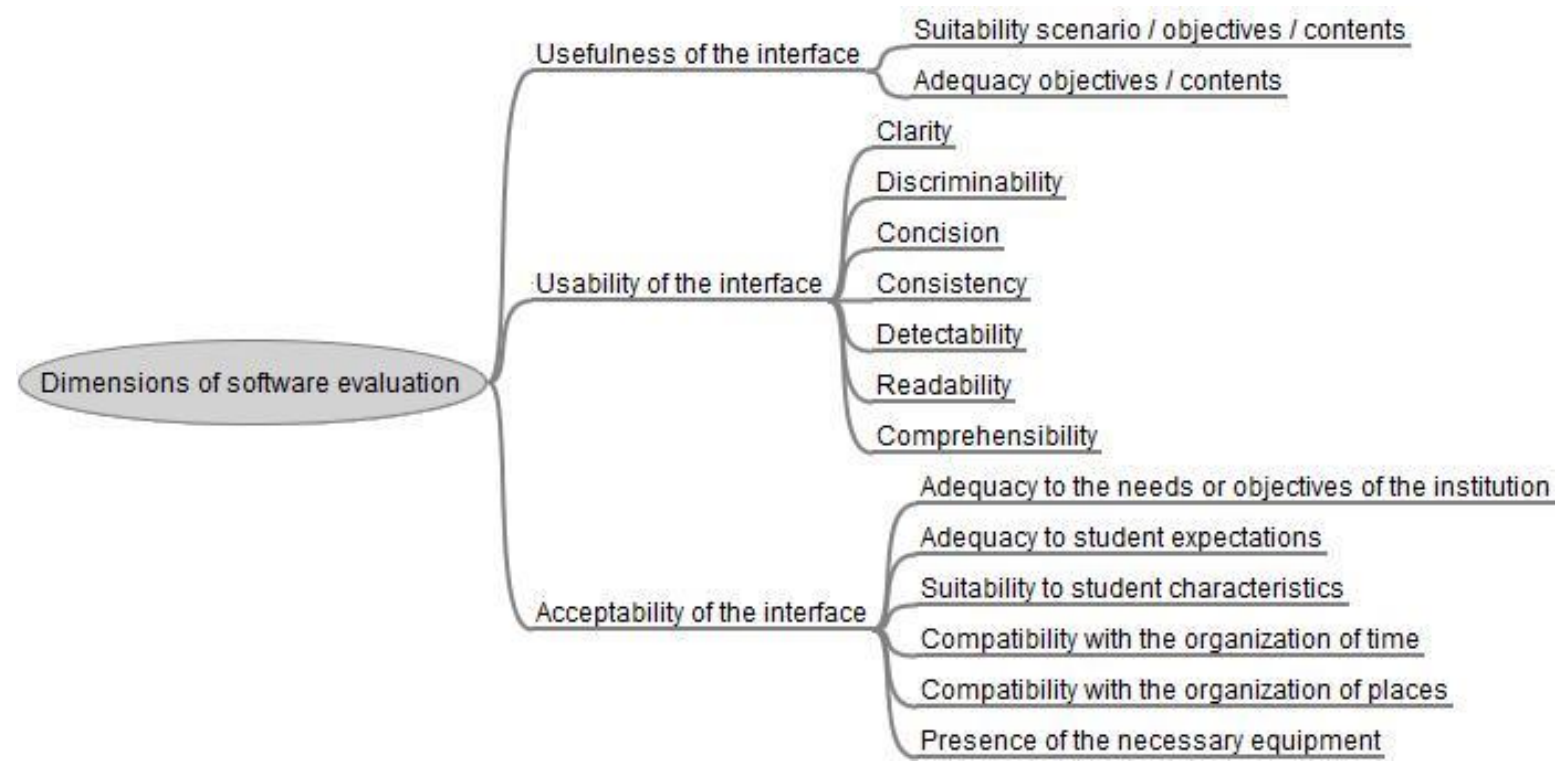

Figure 5. Dimensions of software evaluation

6.4. Explanatory criteria for the relevance of the teaching-learning process

The objective was to collect data to understand factors that may be involved in managing the contingencies of the teaching process. The theoretical framework articulating the instrumental approach, activity theory, software ergonomics and the analysis of teachers' pedagogical practices, made it possible to deduce the explanatory factors of relevance of the teaching-learning process of the teacher mechanical design using modeling and simulation tools.

The first factor relates to the teacher's profile, the second to the institutional context, the third to the software ergonomics, and finally the fourth to the teacher interaction with the modeling and simulation tool of the teachinglearning process. The data collected come from questionnaires, semi-directed individual interviews, and observations from these teachers. The data collected is essentially qualitative.

The table below presents the criteria that contribute to the relevance of the mechanical design teaching process using CAD software.

Table-1. Criteria for the relevance of the mechanical design teaching process using CAD software

\begin{tabular}{|c|c|c|c|}
\hline \multirow{10}{*}{ 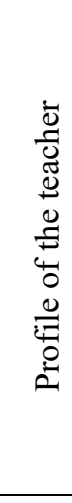 } & Social profil & \multirow{18}{*}{ 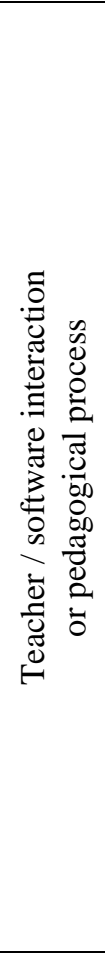 } & Content Knowledge (CK) \\
\hline & 1. Gender & & 28. Prerequisites in mechanical design \\
\hline & 2. Language & & $\begin{array}{l}\text { 29. Prerequisites for using the modeling } \\
\text { tool }\end{array}$ \\
\hline & 3. Age & & 30. Learning objective \\
\hline & Study & & 31. Adequacy objectives / course contents \\
\hline & 4. Specialty & & Knowledge related to pedagogy (PK) \\
\hline & 5. Level of education & & 32. Reference teaching model \\
\hline & The teacher's experience & & Content Pedagogy Knowledge (PCK) \\
\hline & 6. Teaching in mechanical design & & 33. Content structuring \\
\hline & 7. Using the CAD software & & 34. Presentation of the content \\
\hline \multirow{8}{*}{ 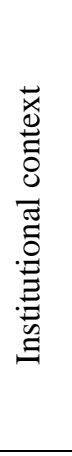 } & Institution & & $\begin{array}{l}\text { 35. Suitability terms and notation between } \\
\text { software and theoretical course }\end{array}$ \\
\hline & 8. Institution type & & 36. Anti-return actions \\
\hline & 9. University Policy & & 37. Presentation of proposed activities \\
\hline & Class & & 38. Relevance of proposed activities \\
\hline & 10. Teaching level & & Knowledge related to technology (TK) \\
\hline & 11. Class size & & 39. Modeling tool used \\
\hline & 12. Prescription volume & & 40. Activity used \\
\hline & $\begin{array}{l}\text { 13. Competences / objectives; Hourly } \\
\text { volume }\end{array}$ & & $\begin{array}{l}\text { Knowledge of technology related to } \\
\text { pedagogy (TPK) }\end{array}$ \\
\hline
\end{tabular}




\begin{tabular}{|c|c|c|}
\hline \multirow{17}{*}{ 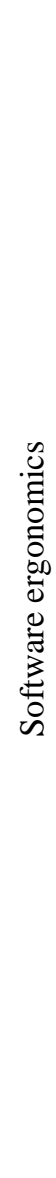 } & Usefulness of the interface & $\begin{array}{l}\text { 41. Presentation of contents by the } \\
\text { modeling tool }\end{array}$ \\
\hline & 14. Suitability objectives / contents & $\begin{array}{l}\text { Content-related technology knowledge } \\
\text { (TCK) }\end{array}$ \\
\hline & $\begin{array}{l}\text { 15. Suitability scenario / objectives / } \\
\text { contents }\end{array}$ & 42. Adequacy contents / modeling tool \\
\hline & Usability of the interface & $\begin{array}{l}\text { Technological Knowledge in Teaching } \\
\text { Practices and Disciplinary Content } \\
\text { (TPCK) }\end{array}$ \\
\hline & 16. Clarty & $\begin{array}{l}\text { 43. Relevant content presentation by the } \\
\text { modeling tool }\end{array}$ \\
\hline & 17. Discriminability & \\
\hline & 18. Concision & \\
\hline & 19. Consistency & \\
\hline & 20. Detectability & \\
\hline & 21. Readability & \\
\hline & 22. Comprehensibility & \\
\hline & Acceptability of software & \\
\hline & 23. Adequacy to teacher expectations & \\
\hline & $\begin{array}{l}\text { 24. Adequacy to the needs or } \\
\text { objectives of the institution }\end{array}$ & \\
\hline & $\begin{array}{l}\text { 25. Compatibility with the organization } \\
\text { of time }\end{array}$ & \\
\hline & $\begin{array}{l}\text { 26. Compatibility with the organization } \\
\text { of places }\end{array}$ & \\
\hline & $\begin{array}{l}\text { 27. Presence of the necessary } \\
\text { equipment }\end{array}$ & \\
\hline
\end{tabular}

VII. RESULTS

In this article, we limit ourselves to the analysis of data relating to didactic action of teachers. These data from the teacher questionnaire, observations and interviews are organized around four items. These later are related to the teacher profile, the institutional context, the software ergonomics and the pedagogical process.

\subsection{Characterization of teachers}

All the teachers observed obey the same characteristics in terms of academic, professional, age and gender profile.

\subsection{Institutional context of intervention}

The teaching-learning situations observed lasted on average two hours of time, in a classroom dedicated to the teaching of mechanical design. They concern on average three classes of twenty-five students in the first year of the DUT "technical University degree" in production. To these elements of institutional context is added the target competence entitled "realization of a numerical model of a mechanical system". This skill from the official program, allows technicians to master the CAD tools in the design office and industrial sectors of mechanics. As part of this study, the teaching-learning situations implemented contribute to the installation of the competency.

\subsection{Process of implementation of teaching-learning situations}

Teachers say they have adopted the innovative design approach. In this context, the objectives assigned to the different teaching-learning situations are linked to the detailed design, a step in the process of producing a product. Socioconstructivism is the pedagogical reference model supposedly adopted by teachers in teaching-learning activities related to the use of the modeling tool. However, in all the teaching-learning situations observed, it is the teacher who determines the pedagogical path in which he shows, has it done individually, then makes the students formulate in order to evaluate the achievements of the teacher learning. By this method, he seeks to make students acquire a know-how by simple or deferred imitation. This practice is inspired more by demonstrative methods. Whereas, for the stated socio-constructivist model, it is most often suggested to the teacher to create a problem situation with material that makes it possible to use the tests, the errors and the groping to learn. It must also mobilize the personal experience of the student or that of a group of students to assess the situation and solve the problem with their means. Intra-cognitive work and peer-to-peer collaborative work are promoted. The pedagogical culture of the teacher could be a quality input for the arrangement of teaching-learning situations. The modeling tool in question was used through several activities, including the design of mechanical parts shapes, 
the dimensioning of mechanical parts, the assembly of mechanical parts and the animation of mechanical systems. From an ergonomic point of view, the modeling tool facilitated the learning of the contents to be taught because of their coherence with the contents of the interface. Its relevance is a guarantee of quality learning. From the point of view of utility, the interface facilitated the achievement of learning objectives. This confirms its effectiveness and efficiency. In the same sense, the actors find the functionality of the interface quite satisfactory. The latter is characterized by the clarity of the content displayed on the interface, the distinction of information, the display density and the consistency of the information present on the interface. Also within the framework of the functionality, it is positively appreciated the facility of localization and reading present information on the interface. Finally, it is emphasized the ease of understanding the meaning of the icons on the interface. Moreover, the actors reveal that the modeling tool has met their expectations and the needs of the institution. It is also considered compatible with the organization of time and places.

\section{DISCUSSIONS}

We have examined factors that may be involved in the contingency planning of the mechanical design teaching process. The study reveals the importance of the teacher's profile in the teaching-learning process of mechanical design. In the profile, we looked at the impact of the teachers' professional experience on the process. While work experience contributes to the mastery of skills for teaching, it is also a factor that can influence the conceptions of the profession. Huberman has shown that teachers' concerns evolve over time by moving successively from selfcenteredness to task as well as students [32]. Observations confirm that these experienced teachers have become more concerned with thinking about the task. In other words, a logic of education that most often concerns beginners, they are in a logic of learning. Which constitutes a real paradigm shift.

Regarding the institutional context, its conception of the institution's programs reveals its didactic-type orientations (skills approach) which suggests the theory of activities as the foundation of learning. In this case, all activities would be designed to effectively contribute to the installation of the target skill.

From the point of view of the ergonomics of the software, the use of the utility, usability and acceptability of modeling tools are levers by which the teacher arouses the need, gives rise to interest and motivation to trigger the activity of the learner. Thus the joining of these three variables reinforces the teacher's desire to use the modeling and simulation tool. Behaviorist conception, still largely dominant in observed practices, cannot contribute effectively to the student's cognitive and metacognitive development. The most recent developments in the behaviorist paradigm have made it possible to renew and enrich teaching models, integrating, in particular, elements of the cognitivist paradigm, to adapt them to ICT [33]. This opportunity could be extended to modeling and simulation tools. In this context, two strong ideas are common to all models of education resulting from this paradigm (cognitivism). As a first step, learning is conceived as a process of building knowledge, not as a process of acquiring knowledge. Secondly, teaching activities are that help build knowledge rather than knowledge transfer sessions [34]. In the context of observed practices, related to teachers' statements, it can be deduced that the question of constructivism is still at the state of the discourse. There is no question of inculcating knowledge, even if it is practical. What is needed is to get students to build and co-build themselves. Unfortunately, no opportunity in this sense has been exploited. The students were there in groups, but each worked individually imitating the teacher. No interaction between students, but hierarchical relationships between student and teacher. This, notwithstanding the famous remark of Piaget: the intellectual schemes pass better between peer than hierarchical report.

\section{CONCLUSION}

The purpose of this study was to analyze factors that could intervene in the management of the contingencies of the teaching process, through a joint activity in the context of the teaching of mechanical design through the prism of modeling and simulation tools. In conclusion of our research work, we highlight the impact of the factors retained on the teaching-learning process from mechanical design to the prism of modeling tools. This work allowed the analysis of a teaching-learning situation proposed by the teacher based on the official programs, then the analysis of the activity of the students when they are confronted with problem-solving situations of design as part of the teaching of mechanical design in industrial sciences and technologies.

\section{REFERENCES}

[1] Abouelala, M. (2015). Evaluation des outils de modélisation et de simulation dans le domaine de l'enseignement de la fabrication mécanique (cas des logiciels de la FAO), Thèse de Doctorat, Université Mohammed V - Souissi. https://www.theses.fr/2015AIXM3056

[2] Bonnardel, N. \& Didier, J. (2020). Brainstorming variants to favor creative design. Applied Ergonomics, 83, 102987. https://doi.org/10.1016/j.apergo.2019.102987 
[3] Didier, J. (2017a). Didactique de la conception et démocratie technique. Dans Didier, J ; Lequin.Y et Leuba. D. (dir.), Devenir acteur dans une démocratie technique. Pour une didactique de la technologie (p. 135-154). Belfort-Montbéliard : UTBM

[4] Pellerin, G. (2015). Lagrange, J.-B. (dir.). (2013). Les technologies numériques pour l'enseignement. Usages, dispositifs et genèses. Toulouse : Octares. Formation et profession, 23(1), 92-94. http://dx.doi.org/10.18162/fp.2015.a56

[5] Lebahar, J.-C. (2007). La conception en design industriel et en architecture. Désir, pertinence, coopération et cognition. Paris: Hermès-Lavoisier.

[6] Safin, S. (2011). Processus d'externalisation graphique dans les activités cognitives complexes : le cas de l'esquisse numérique en conception architecturale individuelle et collective. PhD Thesis, University of Liège, Belgium. http://hdl.handle.net/2268/110740

[7] Bécheau, V. \& Bourgeois, M. L. (2013). Glossaire du designer-Essai. Bruxelles: La Muette-Le bord de l'eau.

[8] Bonnardel, N. (2009). Activités de conception et créativité : de l'analyse des facteurs cognitifs à l'assistance aux activités de conception créatives. [Activities Design and Creativity: From the analysis of cognitive factors to assistance to creative design activities] Le Travail Humain, 72(1), 522.

[9] Goldschmidt, G., (2014). 'Modeling the Role of Sketching in Design Idea Generation', in A. Chakrabarti, Blessing, L.T.M. (Eds.), An Anthology of Theories and Models of 161Design: Philosophy, Approaches and Empirical Explorations (pp. 433-450). Springer. https://doi.org/10.1007/978-1-4471-6338-1_21

[10] Oosterman, B. (2001). Improving product development projects by matching product architecture and organization. $\quad \mathrm{PhD} \quad$ Thesis, Groningen University, Netherlands. file:///C:/Users/hp15/AppData/Local/Temp/thesis.pdf

[11] Rabardel, P. (1995). Les hommes et les technologies, une approche cognitives des instruments contemporains. Paris: Armand Colin.

[12] Mishra, P., Koehler, M. J. (2006) .Technological Pedagogical Content Knowledge: A Framework for Teacher Knowledge. Teachers College Record, 108 (6), 1017-1054. 4. https://doi.org/10.1111/j.14679620.2006.00684.X

[13] Fischer, H. E., Borowski, A., \&Tepner, O. (2012). Professional Knowledge of Science Teachers. In B. J. Fraser, K. Tobin, \& C. J. McRobbie (éd.), Second International Handbook of Science Education (p. 435-448). Dordrecht: Springer Netherlands.

[14] Ohle, A., Boone, W. J., \& Fischer, H. E. (2015). Investigating the impact of teachers' physics CK on students'outcomes. International Journal of Science and Mathematics Education, 13(6), 1211-1233. http://doi.org/10.1007/s10763-014-9547-8

[15] Tochon, F. V(1993). L'enseignant expert, Paris, Nathan.

[16] Hérold, J.-F. (2019). Un modele de la situation d' 'enseignement-apprentissagepour mieux comprendre l'activité de l'éleve en classe.' Revue des sciences de l'éducation, 45(1), 82-107. https://doi.org/10.7202/1064607ar

[17] Sanchez, E., \& Monod-Ansaldi, R. (2015). Recherche collaborative orientée par la conception: Un paradigme méthodologique pour prendre en compte la complexité des situations d'enseignement-apprentissage. Éducation \& Didactique, 9(2), 73-94. https://doi.org/10.4000/educationdidactique.2288

[18] Dupin de Saint-André, M. (2011). L'évolution des pratiques à voix haute d'enseignantes expertes et leur influence sur le développement de l'habileté des élèves du préscolaire à faire des inférences (Thèse de doctorat inédite). Université de Montréal. . http://hdl.handle.net/1866/6854

[19] Daudelin, C., Lefebvre, S., Brodeur, M. Mercier, J., Dussault, M. et Richer, J. (2005). Évolution des pratiques et des conceptions d'enseignants du primaire en contexte de développement professionnel lié aux TIC. Revue des sciences de l'éducation, XXXI(1), 79-110. . https://doi.org/10.7202/012359ar

[20] Thouin, M. (2014). Réaliser une recherche en didactique. Éditions MultiMondes.

[21] Vergnaud, G. (2012). Préface. In M.-L. Elalouf, A. Robert, A. Belhadjin\& M.-F. Bishop, (Éds), Les didactiques en question(s) (pp. 9-13). Bruxelles : De Boeck.

[22] Biagioli, N. (2014). Quelles relations les élèves établissent entre les apprentissages langagiers extrascolaires, les apprentissages langagiers de la discipline français et ceux des autres disciplines ? Le point de vue de l'interdidactique. In J.-L. Dufays\& B. Daunay (Éds.). Didactique du français langue première : le côté des élèves (p. 157-173). Bruxelles : De Boeck.

[23] Parks, S. (2000). Same task, different activities: Issues of investment, identity and use of strategy. TESL Canada Journal, 17 (2), 64 - 88. . https://doi.org/10.18806/tesl.v17i2.890

[24] Vygotsky, L. (1985). Pensée et langage. Paris: Éditions Sociales.

[25] Engeström, Y. (1999). Activity theory and individual and social transformation. In Y. Engeström, R. Miettinen, \& R.- L. Punamäki (Eds.), Perspectives on activity theory (pp. 19-38). Cambridge University Press.

[26] Léontiev, A. (1984). Activité, conscience, personnalité. Trad. Geneviève Dupond et Gilbert Molinier. Moscou : Editions du Progrès. 
[27] Engeström, Y. (1987). Learning by expanding. An activity-theoretical approach to developmental research. Helsinky: Orienta - Konsultit.

[28] Abouelala, M., Taha Janan, M., Brandt-Pomare, P. (2015). Methodology of selecting CAM software package for education based on a questionnaire. International Journal of Mechanical Engineering Education, pp.1-17. . https://doi.org/10.1177/0306419015588397

[29] Baggen, R., Correia, J., Schill, K etVisser, J. (2011). Standardized code quality benchmarking for improving logiciel maintainability. Logiciel Quality Journal, pages 1-21. . https://doi.org/10.1007/s11219-011-9144-9

[30] ISO 9241. (1998). Ergonomic Requirements for Office Work with Visual Display Terminals.

[31] Tricot, A., Plégat-Soutjis, F., Camps, J.-F., Amiel, A., Lutz, G., \&Morcillo, A. (2003). Utilité, utilisabilité, acceptabilité : interpréter les relations entre dimensions de l'évaluation des EIAH. In C. Desmoulins, P. Marquet \& D. Bouhineau (Dir.), Environnements informatiques pour l'apprentissage humain (pp. 391-402). Paris: ATIEF/INRP

[32] Huberman, M. (1984). Vers une biographie permanente de l'enseignant. Education Permanente, (72-73), 183197.

[33] Gagné, R.M., Briggs, L.J. \& Wager, W.W. (1992, 4th ed.). Principles of instructional design. New York, NY: Harcourt, Brace.

[34] Duffy, T. \& Cunningham, D.J. (1996). Constructivism: Implications for the design and delivery of instruction. In D.H. Jonassen (Ed.), Handbook of research for educational communications and technology (pp. 170-198). New York, NY : Macmillan. 